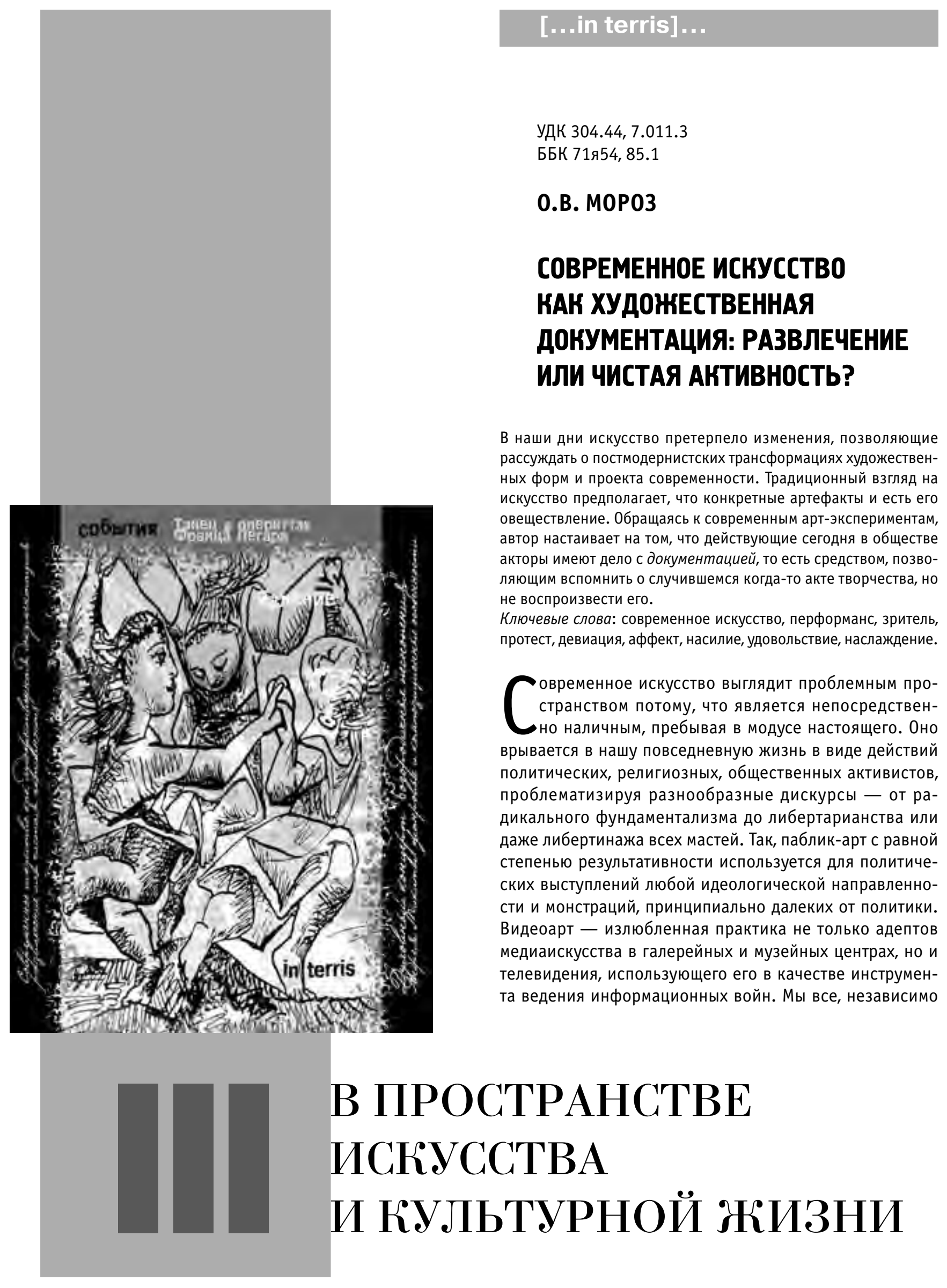


от накопленного профессионального и повседневного опыта, интенций и интересов, будучи причастны окружающей действительности, оказываемся включенными в актуальные художественные практики и, соответственно, вынуждены разделять ответственность за их тексты.

В такой ситуации необходимость произвести качественный анализ современного искусства вызывает к жизни яростные споры о его природе. Однако наблюдение за профессиональными дискуссиями на этот счет рождает неудовлетворительный вывод: свести постоянно трансформирующиеся, текучие современные арт-практики к каким-то ригидным определениям можно, только признав гегемонию определенной идеологической оптики, например, ставшего вновь модным у европейских интеллектуалов марксизма или постоянно обновляемого «политического психоанализа». И хотя подобный ангажированный взгляд далек от текстов традиционного искусствознания, во многом представляющих устаревшую позицию обсуждения предмета нашего исследования, его применение не проясняет ситуацию. 0 н, как и прежние стратегии экспликации смыслов искусства, лишь нагружает художественные тексты дополнительными комментариями. Они же, вопреки ожиданиям, отдаляют и зрителя, и исследователя от реального художественного произведения, то есть той совокупности вопросов о природе реальности, которые не могут быть заданы конвенциональным языком и потому артикулированы языком метафор. Вместо множественности субъективных прочтений или голоса самого автора, который всегда предполагает интеллектуальную игру-дешифровку, комментарий предлагает ограниченный набор клише.

Большим упрощением представляются попытки объяснить аутодеструктивные элементы творчества таких перформансистов, как Йоко Оно или Марина Абрамович, с помощью одного лишь психоаналитического взгляда на девиации или инструментария постколониальных исследований ${ }^{1}$.

Фильмы чешского кинорежиссера и аниматора Яна Шванкмайера вряд ли поддаются однозначной интерпретации как тексты о манипуляции сознания человека биополитическими и соответствующими психологическими стратегиями вездесущей репрессивной власти².

Подход к анализу произведений отечественных концептуалистов (Д. Пригова, В. Сорокина, И. Кабакова и многих других) как к способам деконструкции советской культуры, также не кажется однозначно выигрышным³. Подобные замечания можно множить бесконечно, но все они вращаются вокруг одной проблемы - непростительной редукции смыслов современного искусства, которую производит наделение ярлыками любых его форм (вне зависимости от национальной, темпоральной, даже иде-

\footnotetext{
${ }^{1} 0$ роли психоанализа в арт-практиках Йоко 0но см.: [1]. 06 эротизации народной культуры в творчестве М. Абрамович см.: [2].

${ }^{2} 0$ фрейдистском толковании творчества Я. Шванкмайера см.: [3]. 0 чешском кинематографе и месте Я. Шванкмайера в нем см.: [4].

${ }^{3} 0$ пересмотре советской культуры кругом авторов московского концептуализма см.: [5].
}

ологической принадлежности). В определенном смысле присвоение четких индикаций - это тупик для ризоматических интерпретаций, насаждение гегемонии одного языка, что, как считают современные философы вслед за М. Фуко, - подлость [6, с. 188].

Но, возможно, полагают некоторые теоретики современного искусства, художественный комментарий, порожденный куратором или иным специалистом-теоретиком, необходим арт-практикам как защитная амальгама? [7, c. 153]. Вместо того чтобы предоставлять зрителю свободу угадывать смыслы в представляемых работах, художники рады переложить на кураторов ответственность за концептуальное тематизирование своего творчества и, таким образом, защищаются от непонимания публики? В конце концов претензии о непонятном или, в иных категориях, некачественном изображении реальности, которые могут быть предъявлены автору, уступают место требованиям к куратору предоставить доступное и узнаваемое объяснение. И если комментарий представляет собой совокупность удобных для зрителя понятий, то он придает процессу прочтения художественного текста определяемый и довольно однозначный линейный вектор. В таком случае комментарий работает как «эффективная» метка, тэг, определяющий аудиторию искусства, его рентабельность и актуальность, соответствие модным тенденциям. Так, организованная в конце 2012 года Мультимедиа Арт Музеем выставка работ известного британского художника Марка Куинна сопровождалась масштабными комментариями его директора - Ольги Свибловой.

Интервью Свибловой с этим представителем группы Young British Artists, занявшим огромное пространство стены на одном из этажей музея, с точки зрения кураторов было призвано легитимировать творчество Куинна по одной причине: оно было построено на довольно снобистском объяснении «профанам» смысла всех представленных работ в манере «а что же все-таки хотел сказать автор?».

Впрочем, такое взаимодействие артистических акций и художественной критики может корректно функционировать только в том случае, если рассматривать продукт художественной активности как артефакт, как овеществление некоего общего представления об «искусстве». Такое искусство свободно чувствует себя в контексте культуры потребления, поскольку работает на рынке создания «просто красивых вещей», «ценностей консьюмеризма», достойных, пусть весьма престижного, но пассивного созерцания/приобретения. «Артхаусное» кино или модный biopic, «цифровое» или «дигитальное» искусство, различные виды и жанры фотоискусства успешно продаются в формате «публичных лекций» на медийных площадках, которые основаны на превращении образования в «модный вид досуга» [8]. Однако востребованность таких образовательных бизнес-претензий не всегда согласована с интенциями создателей современного искусства, которые все чаще не ставят перед собой задачи пополнения архива ценностей, предметов и методов отражения реальности, «покупка» которых доставляет зрителям удовольствие. 
Скорее, они заинтересованы в провоцировании изменений установок гедонистически-потребительского общества, заключающихся в том, что сегодня цивилизованному человеку предлагают рафинированный образ удовольствия. Художники-активисты исходят из рассуждений о том, что капитализм как система построен на безграничной потребности накопления капитала [9, с. 36], что в повседневности выражается в безысходности и бесконечности консьюмеризма.

Однако для того, чтобы общество потребителей продолжало поддерживать механизм получения мега-прибылей, оно должно быть здорово. Поэтому экономические и политические машины регулируют то удовольствие, которое может испытать человек, с тем, чтобы он оставался работоспособным и обеспеченным. Как написал недавно С. Жижек, если нам предлагают пищевые удовольствия, то они должны быть очищены от элементов, представляющих угрозу нашей биологической стабильности [10, с. 100]. То же можно сказать и обо всех других способах наслаждаться жизнью - им следует быть предельно безопасными, то есть выхолощенными.

Так, все практики, даже связанные с опасным времяпрепровождением, определяются сегодня маркетингом. А потому любое желание человека реализуется посредством различных отработанных маршрутов, опробованных стратегий индустрии развлечений, позволяющих нам чувствовать себя спокойно, защищенно. Вы хотите путешествовать, ощущая себя первопроходцем-пионером, а вам предлагают насладиться благоустроенными уголками Юго-Восточной Азии, лишая возможности познакомиться с другой культурой, пролегающей вдали от туристических «троп». Вам претит официальная культура, и вы ищете отдушину в андеграундных практиках (например, стриткультуры или даже нарко-культуры), но в приближении они оказываются уже легализованными и «отредактированными», приглаженными. Вы страстно желаете прикоснуться к «высокому» (в искусстве, науке), а вместо этого получаете чаще всего в лучшем случае рекламу в жанре infotainment, рассказывающую о банальной рентабельности любого продукта творчества как о качестве, к которому необходимо стремиться, чтобы стать «успешным», то есть продаваемым и покупаемым.

Современному искусству, по крайней мере наиболее многообещающим его образцам, такие интенции не близки. Оно наследует взрывным настроениям модерна и по определению является протестным и провокаторским. Оно желает научить своих зрителей наслаждаться, то есть стремиться к экстремальным видам познания, не ограниченным утилитарными представлениями о «принятом». Только так можно прорвать бесконечную циркуляцию пустотного удовольствия, которое не приносит удовлетворения, но толкает потребителя на постоянное повторение акта приобретения. И только так можно действительно открыть для себя какие-то новые горизонты, не ограниченные рамками дозволенного, разрешенного, одобряемого, а значит, стереотипного и потенциально ошибочного.
Стоит заметить, что сомнительность возможности «получать удовольствие» от включения в практики современного искусства ощущается как очевидность любым зрителем - и профессионалом, и обывателем. Ни в проспектах выставок современных художников, ни в анонсах новых книг писателей-постмодернистов мы не найдем обещания блаженства от эстетически неприятных и зачастую этически неприемлемых перформансов, хепенингов, инсталляций и реди-мейдов, форма и содержание которых нередко граничат либо с симптоматикой Ар Брют, либо с вандализмом и кощунством. Однако, если modern/ contemporary art - это настолько неприлично, почему оно настолько востребовано?

Ответом на это недоумение может служить кардинальная смена оптики, позволяющая увидеть в искусстве не традиционную форму производства значений и смыслов культуры, а эксперимент по их ризоматическому остранению. Если задачей художника является создание коммуникативных технологий, необходимых для обсуждения зашифрованных, табуированных в обществе вопросов, то смысл его действий - только лишь документация художественного исследования, направленного на метафорическое и карнавальное выявление подлинных, непроговариваемых и скрытых смыслов культуры.

Не получая готовых ответов на вызовы современности у экспертов, которым делегированы полномочия «нейтральных» комментаторов, художники сами предпринимают аналитические усилия, предлагая зрителям как минимум эффект присутствия.

Носители культуры испытывают кризис идентичности. Перформансист предложит эпатирующее представление, в ходе которого потребует от зрителя физически поэкспериментировать со своим телом как носителем политической, религиозной, национальной, гендерной самости ${ }^{4}$. Общество переживает кризис доверия к капиталистическим и мультикультурным путям развития, но не знает, в какие формы облечь свой протест - писатель погрузит их в поэтические способы объяснения репрессирующего давления микрофизики власти на любые структуры повседневности ${ }^{5}$. Художник покажет, как внутренняя иммиграция и эскапизм могут перерасти во вполне настойчивое и действенное, хотя не обязательно насильственное требование трансформации всей сети социальных связей ${ }^{6}$. Наконец, если нам неочевидно, где проходят в культуре границы дозволенного/запрещенного, нормального/ненормального и как соотносятся в

\footnotetext{
${ }^{4}$ Например, см. перформансы М. Абрамович «Ритм 0», «Балканское барокко», «Дом с видом на океан», «Art must be beautiful, artist must be beautiful» и другие.

${ }^{5}$ Например, см. тексты В. Сорокина «0чередь», «Норма», «Тридцатая любовь Марины», В. Пелевина «Омон Ра», «Жизнь насекомых», «Затворник и Шестипалый», «Т», В. Ерофеева «Русская красавица», «Жизнь с идиотом», «Энциклопедия русской души» и т. д.

${ }^{6}$ См., например, работы Бэнкси на Израильском разделительном барьеpe, а также на различных социально важных объектах: зданиях музеев, зоопарков, клиник сексуальных проблем и т. д. Пересмотру разнообразных стереотипов посвящены сюрреалистические фотографические опыты, в том числе, работы Клод Каон.
} 
этом смысле усвоенные культурные коды, официальная легитимация и здравый смысл, мы вправе ожидать от театральных и кинематографических текстов в жанре вербатим соответствующие ответы ${ }^{7}$.

Интерес к подобного рода исследованиям со стороны разной публики продиктован очевидным аффективным воздействием искусства, которое сегодня, в контексте все возрастающего значения клиповых механизмов функционирования сознания, чрезвычайно высоко [10, с. 17]. Современное искусство принадлежит миру «здесь и сейчас», но зачастую рассуждает с позиций вневременных переживаний, которые могут помочь в приоткрывании реальности, скрытой сегодня ширмой информационного, идеологического и прочих шумов.

Документация таких художественных исследований осуществляется с помощью множества стратегий, которые, впрочем, работают в соответствии с близкими методологическими принципами.

Так, современное искусство обращается к непосредственному изучению экстремальных, крайних состояний культуры, переживаний ее радикального разрушения. Эти нарушения культурной ткани представляют собой неприятный, катастрофический опыт, который никогда не может быть окончательно осмыслен или понят. Этот комплекс болезненных симптомов культуры не укладывается в привычные представления о внешнем мире, а потому оказывается вытесненным [11, с. 39]. Однако именно он включает в себя потребности, импульсы и стремления, необходимые человеку, пусть и представляющие для него опасность. Их изучение - попытка картографировать те желания и страдания, которые и делают нас людьми.

Пример осуществленного в соответствии с подобной методологией арт-исследования представляют художественные опыты немецкого анатома Гюнтера фон Хагенса, изобретшего оригинальный способ пластинации живых организмов. Технически способ работы фон Хагенса это модификация процедур бальзамирования: жидкости и жиры в телах, подлежащих консервации, заменяются специально разработанным для этого активным пластиком. В результате ткани экспонатов сохраняют свою фактуру и структуры в неизменном виде вплоть до микроскопического уровня. В дальнейшем получившимся объектам можно придавать любые формы, компоновать их в скульптурные композиции: забальзамированные трупы людей играют в шахматы, занимаются сексом, катаются на коньках, позируют для fashion-фотографов, играют на музыкальных инструментах. Подобная техника позволяет лишить «препараты» специфического запаха, что несколько облегчает знакомство с экспонатами, которые обычно представлены практически в «освежеванном» виде. Отсутствие запаха и красочность цветового оформления важны и потому, что основной вид экспонирования достижений этого таксидермиста - создание передвижных

\footnotetext{
${ }^{7}$ См., например, спектакли театра Театр.doc или пьесу В. Преснякова «Изображая жертву», а также одноименный фильм К. Серебренникова по этой пьесе.
}

художественных выставок на больших площадках, специально неприспособленных для анатомических опытов, но открытых массовому зрителю («The Human Body», «Body World», «Körperwelten \& Der Zyklus des Lebens» [12]).

Сам фон Хагенс считает себя авангардистским продолжателем традиций анатомических театров эпохи Возрождения, занимающимся просвещением своего зрителя. С одной стороны, демонстрация человеческого тела в его физиологической обнаженности должна, с его точки зрения, пропагандировать здоровый образ жизни. Как рассказывали организаторы киевской выставки фон Хагенса, экспозиция «The Human Body» (сентябрь - декабрь 2012 года) состоит из отдельных галерей, каждая из которых тематизирует тот или иной элемент человеческой анатомии. Посетитель выставки фон Хагенса обычно может ознакомиться с обзором человеческого тела, начиная от скелета и далее - со скелетно-мышечной, респираторной, пищеварительной, нервной, циркуляторной и мочеполовой системами, а также заглянуть в будущее человеческого тела, построенного на принципах сохранения здоровья и благополучия.

Отдельного упоминания в проспектах выставок всегда удостаивается то, что на любом ее этапе зрителя может проконсультировать специалист-медик, который квалифицированно ответит на все интересующие вопросы [13]. Таким образом, представляя вниманию посетителей выставки зачастую изношенные человеческие тела, фон Хагенс наглядно демонстрирует нам все «прелестные» последствия культуры потребления и других практик повседневности. Такой способ продвижения бережных способов ухаживания за телом выглядит гораздо действенней, нежели агрессивно навязываемый менеджментом в течение последних 30 лет концепт «healthy lifestyle».

С другой стороны, экспонаты, буквально вывернутые наизнанку, указывают на уязвимости нашей телесности, а зрителей провоцируют на осознание своей эмоциональной и интеллектуальной зашоренности, слабости. Каждый год знакомство с творчеством фон Хагенса заканчивается требованиями судебных процессов над «извращенцем» с выяснением того, почему его активной «психопатической» активности не мешают власти и можно ли как-то ограничить его вполне легитимную деятельность, которая не укладывается в обывательские представления об этическом и эстетическом.

Круг почитателей таланта немецкого медика растет и не только за счет студентов специальных образовательных учреждений. Его популярность объясняется новаторским способом разговора со зрителем, к которому он прибегает. Фактически анатом-художник старается говорить с нами, профанами, на медикализированном языке метафор, поднимая с его помощью вопросы, практически запрещенные к открытому обсуждению. Что такое человеческая жизнь? Какова ее ценность? Можем ли мы поступаться как будто априорно установленными этическими нормами с тем, чтобы познать себя и, познав, сконструировать новые, более безопасные, парадигмы социальных связей? Обладаем ли мы возможностями неполитическо- 
го, внеидеологического пересмотра любых - рыночных, семейных - отношений в поисках настоящей, действительной свободы? Или мы настолько детерминированы институтами и процедурами наших политических и цивилизационных систем, что не можем вместить в собственное сознание что-то, лежащее за пределами компетенций этих механизмов? [10, с. 166-167]. Как показывают наблюдения за законодательными решениями в сфере биополитики, официальные ответы на эти вопросы всегда ангажированы заигрыванием режимов либо с «народным контролем», либо с корпоративно-олигархическими представлениями. Между тем, разрешение любых сомнений никогда не может быть спущено откуда-то «сверху», оно может и должно родиться как рефлексия, документация собственных ощущений носителей культуры.

Из этого интуитивного зрительского приближения к интенциям фон Хагенса рождается понимание конечной цели его творчества, не заключающейся, разумеется, в отборе желающих завещать свое тело науке, который осуществляют его помощники по результатам проведенных выставок. Итогом его работы становится активация механизмов сомнения в любых институциональных формах, в любых предписаниях. Эти сомнения должны выражаться не в бунтах девиаций, но в артикуляции вопросов, пусть самых наивных. На такие вопросы, которыми должен задаваться каждый, возможно, уже есть ответы, просто сегодня мы апеллируем с нашей озадаченностью не к тем структурам. Скажем, медицина, как откровенно показывает фон Хагенс, давно сформулировала мнение относительно проблем эвтаназии, трансплантологии, консервации, однако регулируются эти процессы отчего-то государством, которое наделяет себя гиперболизированными экспертократическими полномочиями.

Впрочем, есть и другое методологическое измерение арт-исследования, направленного на документацию случившегося художественного события. Если выставки фон Хагенса - пример сложной и неоднозначной интервенции художественного в жизнь, создание необычных жизненных обстоятельств с целью эпатажа, то практики перформансов, хеппенингов, оказавшись в музее, представляют собой нарративы, рассказы о случившемся когда-то акте творчества. Их задача - документировать авторские откровения-отклонения, побуждая зрителя на ответную откровенность. На фоне работ Гюнтера фон Хагенса или более близких художественным практикам экспериментов Марины Абрамович ${ }^{8}$, которые выглядят не совсем развлечением, этот вид документации - совсем не развлечение.

В данном случае имеются в виду разнообразные аутодеструктивные художественные эксперименты, воплощенные в работах Стеларка, Брюса Лаудена, феминистских опытах Шигеко Куботы, Кароли Шниманн ${ }^{9}$. Эти

\footnotetext{
${ }^{8} 0$ перформансах М. Абрамович см.: [14].

${ }^{9}$ См. один из перформансов «Vagina painting» в исполнении Шигеко Куботы: http://www.artnotart.com/fluxus/skubota-vaginapainting.html; перформансы Кароли Шниманн, в том числе «Внутренний свиток» см. на официальном сайте художницы: http://www.caroleeschneemann. com/index.html
}

и многие другие художники насилуют самих себя, отрезая части собственного тела (ухо, пальцы, язык) и продавая их потом известным галеристам и коллекционерам. Некоторые из них практикуют имплантацию и разные бодимодификации, используют медицинские инструменты, протезы, роботехнические средства и достижения биотехнологий, и результаты этих вмешательств зачастую практически не несовместимы с обычным образом жизни. Другие, в частности художницы-феминистки, предстают обнаженными перед неподготовленной публикой и проводят шокирующие акции, рисуют картины, похожие на полотна Поллока, правда, используя для этого интимные части своего тела. Зачем? Вряд ли исключительно для эпатажа и встряски обывателя, поскольку в таком случае цена шоковой терапии слишком высока.

Возможное недоумение и даже презрение к таким далеким от эстетического акциям разрушится в момент осознания, что все эти действия были порождены в атмосфере чрезвычайной регламентации повседневного, в том числе, и сферы насилия. Вместо обращения к художественным метафорам и иносказаниям, которые в западном обществе оказались к середине прошлого века аннексированы менеджментом культуры, художники с середины 1960-х годов отмечают своим телом отказ от навязываемых конструктов культуры. Они буквально призывают: «Наслаждайтесь тем единственным, чем Вы обладаете на самом деле - своим телом. Не дайте загнать себя в серийные, предлагаемые вам шаблонные образцы нормы. Если нельзя доказать свою индивидуальность, отграниченность от необязательных, но навязываемых правил иным способом - контролируйте свое тело, мешайте ему вписываться в привычные практики потребления». Так рождаются «террористические» перформансы, буквально взрывающие представления о любых нормах: этнических, религиозных, гендерных, профессиональных, этических и эстетических.

Понятно, что в отечественной действительности, и так полной настоящего насилия, подобные акции вряд ли будут востребованы по ряду причин. Во-первых, опыт западных художников-автодеконструкторов уже присвоен, а его повторение в российских реалиях будет лишь несвоевременной копией. Во-вторых, карнавальное отношение к телу в отечественной культуре, нашедшее свое выражение в заимствованной форме бурлеска, подпитывалось традиционным апофатизмом, унаследованным в том числе и советской культурой [15, с. 38-39]. В сумме все эти факторы приводят к идеологическим препятствиям на пути концептуализации языка тела как критического дискурса. Даже «зоофрения» Олега Кулика, признанная российским профессиональным сообществом в качестве классики перформанса конца XX века, часто оценивается как проявление регрессивного психопатологического поведения [16].

Разнообразные чрезвычайно девиантные художественные акты, построенные на описанной выше травестированной аксиоматике, ценны не тем, что они создают «продукты» или «результаты» или маркируют собой возникновение нового пространства искусства. Они важны 
своей современностью, тем, что представляют краткий миг «перехода» от Прошлого как пространства опыта к Будущему как горизонту возможностей [17]. Используя те или иные методы, современное искусство как Настоящее становится местом обитания современного актора, выбирающего возможные варианты будущего на основе прошлого опыта. Это означает, что претендующее на объективность, пассивное «видение» художественного артефакта, которое считается классическим способом чтения текстов искусства, должно смениться иной, активной техникой, легитимной для перцепции современной художественной документации.

Одним из способов взращивания в зрителе новых способов видения арт-практик можно считать широко применяемый сегодня метод медиализации искусства. Вообще погружение в медиа-технологии стало для многих профессионалов необходимой компетенцией. В остальных случаях необходимость активности в сети навязывается маркетингом как признаком «успешности», поэтому люди фактически «вынуждены» бесконечно производить художественные тексты - визуальные, музыкальные, вербальные. Постоянно занимаясь в социальных сетях типа Facebook и Twitter постингом (созданием интернет-сообщений разного объема и уровня доступа, содержащих изображения, музыку и т. д.), ретвиттингом (написанием коротких, до 140 знаков, сообщений, которые объединяются в единую ленту «новостей»), человек оформляет свои идеи и мысли как художественный жест, что становится главным элементом саморепрезентации в виртуальном пространстве.

Художественные практики умело используют эту тенденцию современной информационной культуры в своих целях, рассуждая о расширении и демократизации артсцены. Дигитализация превращает любой визуальный текст в перформанс, каждого участника интернет-коммуникации - в потенциального производителя знаков и символов, художественных практик. В результате, интенция развлечения, которая предполагается в акте наблюдения за произведением искусства, трансформируется. Место удовольствия от восприятия творчества других занимает наслаждение возможностью дешифровки чужой художественной документации и, что гораздо важнее, создания своих собственных концептуальных культурных шифров.

В итоге каждый из нас оказывается создателем художественной документации, как минимум, в масштабах картографирования собственной жизни и истории. А это означает, что мы обладаем возможностью производить собственную чистую активность, собственный образ жизни как личностную «экзистенциальную философию», отражающую наши представления о культурном регулировании. Именно ее мы, усвоив уроки искусства XX века, можем и должны распространять вовне, если желаем изменений. Не этого ли добивалось современное искусство, как-то сказавшее устами своего представителя, поэта и певца Джима Мориссона: «Никакая масштабная революция невозможна без персональной революции, на уровне личности. Она должна сначала случиться внутри»?
С точки зрения современного менеджмента культуры такая протестная позиция выглядит более чем наивно: арт-сопротивление не имеет позитивной «программы действий». Значит, предлагаемое им сложно классифицируемое «наслаждение» можно вписать в привычные практики «удовольствия» и успешно продать как модную активность для, скажем, «креативного класса». Но арт-маркетинг как механизм управления культурными практиками не может просчитать такой поворот сюжета - даже предавая улицы, отказываясь от андеграунда в пользу галерей и социальных медиа, художник террористически взрывает устои институций. Конечно, «артефакты», которые он производит, открыты для приобретения, но взгляд, породивший их, не продается в силу невозможности массового распространения такого герметичного опыта в господствующем арт-диспозитиве. Таким образом, даже, казалось бы, безразлично наблюдая за манипулированием своим творчеством, автор остается своеобразным анархистом. Демонстрируемая им нулевая точка борьбы искусства - самая тайная и, в то же время, действенная хитрость, поскольку тот, кто отказывается от диалога как системы внедрения небольших, пошаговых перемен, готовит почву для настоящей, радикальной активности.

\section{Список литературы}

1. «0диссея таракана» Йоко Оно // Ежедневные новости искусства@Artinfo [Электронный ресурс]. - Режим доступа: http://www.artinfo.ru/ru/news/main/YokoOnoMoscow-2007.htm

2. Саркисян 0. Оптические иллюзии постколониализма // Полит.Ру. 21 октября 2009 [Электронный ресурс]. - Режим доступа: http://polit.ru/article/2009/10/21/3biengar/

3. Левитова В. Ян Шванкмайер через призму чешской культуры // Киноведческие записки. 2005. № 71 [Электронный ресурс]. - Режим доступа: http://www.kinozapiski.ru/ru/ article/sendvalues/328/

4. Терещенко М. Ян Шванкмайер: «Раз в пять лет нам удается найти деньги на съемки, но это не делает меня экспертом в области анимации». Интервью. OpenSpace.ru. 10.03.2010 [Электронный ресурс]. - Режим доступа: http://os.colta. ru/cinema/names/details/16635/?expand=yes\#expand

5. Чухров К. Деиологизация «советского» // Художественный журнал. 2007. № 65-66 [Электронный ресурс]. - Режим доступа: http://xz.gif.ru/numbers/65-66/keti-chukhrov/

6. Фуко М. Ответы философа // Интеллектуалы и власть: Избранные политические статьи, выступления и интервью. 4. 1. - М.: Праксис, 2002.

7. Гройс Б. Современное положение художественной критики // Политика поэтики. - М.: Ад Маргинем пресс, 2012.

8. Theory and Practice: «Мы написали: “Чуваки, лекции - это круто! " И все поверили». Интервью // Slon. 20.07.2012 [Электронный ресурс]. - Режим доступа: http://slon.ru/ business/theory_and_practice_my_napisali_chuvaki_lektsii_ eto_kruto_i_vse_poverili-812475.xhtml

9. Болтански Л., Кьяпелло Э. Новый дух капитализма. - М.: НЛ $0,2011$.

10. Жижек С. Год невозможного. Искусство мечтать опасно. М.: Европа, 2012. 
11. Черноглазов А. Лакан. Приглашение к Реальному... - М.: Проект letterra.org, 2012.

12. Gunter von Hagens' Body Worlds. The Original Exhibition of Real Human Bodies [Электронный peсурс]. - Режим доступа: http://www.bodyworlds. com/en.html

13. «Доктор Смерть» - патологоанатом от искусства. Сенсационная выставка Гюнтера фон Хагенса «The Human Body» в Киеве [Электронный ресурс]. - Режим доступа: http:// uaparty.com/blog/art/7082.html

14. Мороз О.В. Проблемы исполнительского искусства в современных арт-практиках // Художественная культура. 2012. № 5 [Электронный ресурс]. — Режим доступа: http:// sias.ru/magazine/vypusk-5-2012/teoriya-hudozhestvennoykultury/776.html

15. Цивьян Т. Отношение к себе и к своему телу в русской модели мира // Тело в русской культуре: сб. статей. - М.: Новое литературное обозрение, 2005.

16. Могутин Я. «Зоофрения» Олега Кулика оказалась заразной для многих американцев // Митин журнал [Электронный ресурс]. - Режим доступа: http://www.mitin.com/people/ mogutin/kulik.shtml

17. Гумбрехт Х.-У. «Современная история» в настоящем меняющегося хронотопа // нл0. 2007. № 83 [Электронный ресурс]. - Режим доступа: http://magazines.russ.ru/ nlo/2007/83/gu5.html

\title{
А.Б. КОВАЛЕВ
}

\section{ДУХОВНЫЙ КОНЦЕРТ БОГОРОДИЧНЫЕ ПЕСНОПЕНИЯ» АНДРЕЯ МИКИТЫ: ЖАНРОВЫЕ И КОМПОЗИЦИОННЫЕ ОСОБЕННОСТИ}

\begin{abstract}
Жанр многочастного духовного концерта в творчестве одного из ведущих московских композиторов Андрея Микиты - предмет рассмотрения в настоящей статье. Концерт «Богородичные песнопения» написан для смешанного хора a cappella на богослужебные тексты богородичных праздников - Рождества Богородицы, Благовещения, Успения, Покрова. Жанровые и композиционные особенности духовного концерта А. Микиты связаны с наличием в нем, с одной стороны, элементов богослужебно-певческой традиции, с другой стороны - индивидуального авторского музыкального прочтения канонических текстов, чем в значительной степени обусловлена внебогослужебная жанровая ориентация хорового цикла.

Ключевые слова: духовный концерт, хор, богослужение, тропарь, кондак, стихира, знаменный роспев, фольклор.
\end{abstract}

A ндрей Иштванович Микита принадлежит к числу наиболее известных композиторов среднего поколения, работающих в жанровой сфере русской духовной музыки. Родился он в 1959 году в Ленинграде и первые шаги в искусстве делал в Специальной музыкальной школе при Ленинградской государственной консерватории им. Н.А. Римского-Корсакова. Вначале будущий композитор занимался только фортепиано, а с шестого класса и композицией. Среди его ленинградских учителей по композиции - Ю. Симакин, Б. Тищенко, а в Москве - Т. Хренников и А. Чайковский. Важно, что после переезда в Москву юноша полтора года учился у выдающегося мастера Станислава Нейгауза (до его кончины в 1980 году), оказавшего огромное влияние на формиро- вание творческого облика Андрея Микиты как пианиста и композитора. «Именно Станислав Нейгауз, - вспоминает Микита, - доказал мне, что фортепианная игра, исполнительство в целом - это не просто более менее адекватное воспроизведение нотного текста, но сотворчество, акт вдохновения, восприятие и передача Божественных энергий. Заставил задуматься о том, что интерпретация касается не только исполнителя по отношению к композитору, но и композитора по отношению к Божественным идеям. Ты сидишь на берегу Божественной реки, и тебе дают возможность зачерпнуть. Кому-то каплю, кому-то пригоршню. И тут важно не расплескать, не потерять, материализовать адекватно, в меру таланта, который и есть умение не расплескать и донести» [1] . 